\title{
Jurnal
}

Manajemen Kesehatan Indonesia

Volume 7

Nomor 2

Agustus 2019

\section{Analisis Efektivitas Komunikasi Tulis Baca Konfirmasi dalam Sasaran Keselamatan Pasien di Ruang Rawat Inap Rumah Sakit X Jepara}

\author{
Sinta Nurani*, Sudiro** \\ *Mahasiswa Magister Ilmu Kesehatan Masyarakat Universitas Diponegoro, \\ ${ }^{* *}$ Fakultas Kesehatan Masyarakat, Universitas Diponegoro, Semarang \\ Email:dr.sintanurani@yahoo.co.id
}

\section{ABSTRACT :}

Communication is one of the root causes of mismanagement of medical actions, lack of division of labor and coordination between professions as one of the cultural barriers to safety enforcement in hospitals. Hospitals must have a list of permitted or prohibited abbreviations which can often lead to fatal communication errors. Doctors in private hospitals in regions such as the " $X$ " Jepara hospital come from government hospitals, especially specialist doctors. The time that doctors give very little to meet patients and talk with nurses about the patient's health status is also a problem for patient care. General Purpose: To analyze the implementation of communication TBK in an effort to prevent events related to patient safety.

This study uses data collection methods through indepth interviews (indepth interviews) with informants who have been selected and determined in relation to the implementation of the communication process of effective inpatient installation of Jepara X Hospital. Data processing is carried out with four main processes of qualitative data analysis, namely comprehending, synthesizing, theorizing and recontextualizing.
The results of the study show the implementation of communication TBK in an effort to prevent events related to patient safety Application of effective communication requires a confirmation sheet as proof of recording. But this is not yet available at the $X$ Hospital in Jepara. The modern nurse operation with the TBK technique is to use the TBK technique documentation format for each patient each shift, operand notebook, and patient medical record

Keyword: Health Services, Communication, $T B K$

\section{PENDAHULUAN}

Komunikasi merupakan salah satu faktor penyebab kesalahan dalam tindakan medis. Komunikasi yang tidak berjalan dengan baik pada perawat dan dokter dapat berdampak pada kematian pasien khususnya bila terjadi di ruangan yang menangani kondisi pasien kritis. Kesalahan yang sering terjadi dalam komunikasi adalah misskomunikasi verbal antara dokter dan perawat. ${ }^{1}$

Mekanisme koordinasi dalam komunikasi antar petugas kesehatan dan antara petugas kesehatan dengan pasien perlu diketahui organisasi kesehatan untuk dapat meningkatkan keselamatan pasien 
dan mencapai tujuan organisasi secara efektif dan efisien. $^{2}$

Permenkes RI No.169 tahun 2011 tentang keselamatan pasien juga menyebutkan bahwa komunikasi efektif merupakan salah satu sasaran keselamatan pasien sebagai upaya meningkatkan keselamatan pasien. $^{3}$

Hasil studi pendahuluan didapatkan informasi bahwa 6 dari 10 kasus kejadian nyaris cidera di RS X Jepara terjadi akibat komunikasi yang kurang baik antara dokter dan perawat. Terbatasnya waktu dokter untuk berdiskusi dengan perawat juga menjadi salah satu permasalahan di RS X Jepara sehingga komunikasi yang dilakukan selama ini seringkali hanya dalam bentuk telepon.

Komunikasi Tulis Baca Konfirmasi (TBK) merupakan salah satu bentuk komunikasi efektif yang dapat dilakukan oleh petugas kesehatan ketika terjadi keadaan gawat darurat yang mengharuskan komunikasi antara dokter dan perawat dilakukan via telepon dengan tahapantahapan yang telah ditentukan. Tujuan dari penelitian ini adalah menganalisis efektivitas komunikasi TBK di ruang rawat inap RS X Jepara.

\section{METODE PENELITIAN}

Penelitian ini dilaksanakan di Rumah Sakit X Jepara. Penelitian ini merupakan penelitian kualitatif berjenis observasional analitik. Penelitian kualitatif bertujuan untuk menggali informasi lebih mendalam atau untuk mendapatkan penjelasan secara terperinci tentang suatu fenomena atau masalah. ${ }^{4}$ Data primer diperoleh dengan menggunakan alat pengumpulan data berupa pedoman wawancara. Informan utama dalam penelitian ini berjumlah 6 orang yaitu 3 orang dokter dan 3 orang perawat di ruang rawat inap RS X Jepara sedangkan informan triangulasi adalah manajer penunjang di RS X Jepara. Analisis data penelitian ini menggunakan content analysis.

\section{HASIL DAN PEMBAHASAN}

1. Komunikasi Efektif Tulis Baca Konfirmasi

Berdasarkan hasil wawancara mendalam didapatkan informasi bahwa komunikasi efektif sudah dilakukan di RS $\mathrm{X}$ Jepara dengan metode SBAR dan TBK, komunikasi TBK sudah diterapkan di RS $\mathrm{X}$ Jepara namun dalam pelaksanaannya masih belum optimal. Belum ada peraturan di RS X Jepara terkait sanksi yang diberikan kepada petugas kesehatan terkait dengan pelaksanaan TBK yang tidak sesuai dengan prosedur, sosialisasi terkait TBK sudah pernah dilakukan di RS X Jepara.

2. Variabel Ketepatan Identifikasi Pasien Berdasarkan hasil wawancara mendalam didapatkan bahwa proses identifikasi pasien di RS X Jepara didapatkan hasil bahwa semua IU menyatakan proses identifikasi pasien dilakukan sesuai dengan SOP yang berlaku dengan menuliskan data sesuai dengan identitas. Hal tersebut sejalan dengan pendapat IT yang menyatakan proses identifikasi pasien sudah dilaksanakan sesuai dengan SOP yang ada dengan memberikan nomor RM, menuliskan data pasien sesuai dengan identitas yang berlaku dan harus dilakukan secara lengkap, memberi gelang sesuai kondisi pasien. IT menambahkan bahwa selama ini proses identifikasi pasien belum sepenuhnya sesuai SOP seperti dalam 
menuliskan identitas pasien masih ada perawat yang hanya menulis nama dan tanggal lahir saja sedangkan status, pekerjaan, nama ayah/ibu biasanya masih sering tidak diisi.

Alur dan prosedur penerimaan pasien di RS X Jepara didapatkan hasil bahwa semua IU dan IT menyatakan alur prosedur penerimaan pasien di RS X Jepara sudah sesuai dengan SOP mulai dari proses pendaftaran, pengisian formulir sampai dengan pasien dirawat/pulang. Pasien baru dari IGD maupun poliklinik akan diterima di TPPRI untuk di data identitasnya.

Hambatan dalam identifikasi pasien di RS X Jepara 2 IU menyatakan terdapat hambatan misalnya adanya kesalahpahaman pada nama pasien dan hasil lab. 4 IU lainnya menyatakan tidak mengalami hambatan dalam proses identifikasi pasien. IT menyatakan bahwa dalam proses identifikasi pasien sudah sesuai dengan prosedur tetapi masih ada kalanya dilakukan dengan tidak lengkap dikarenakan beban kerja yang tinggi juga kelelahan.

Kotak 2

"Dalam mengidentifikasi pasien dilakukan sesuai SOP tetapi memang masih ada saja kesalahan dalam nama atau kurang lengkap, dikarenakan kelelahan jadi kurang fokus dan ingin cepat selesai"

\section{Variabel Komunikasi Efektif}

Berdasarkan hasil wawancara mendalam didapatkan bahwa komunikasi efektif menurut IU adalah 3 IU meyatakan komunikasi yang berjalan baik dan dapat dipahami satu sama lain dengan jelas dan tanpa kesalahan, 1 IU mengatakan komunikasi efektif dengan SBAR dalam laporan pasien serta tindak lanjutnya dan TBK untuk komunikasi via telepon, 2 IU menyatakan komunikasi yang berjalan dua arah. IT menyatakan komunikasi efektif adalah komunikasi yang terarah, mudah dimengerti dan bisa dipertanggung jawabkan.
Kekurangan dalam komunikasi antara dokter, perawat dan pasien menurut IU adalah 5 IU menyatakan komunikasi terlalu singkat dan tidak detail karena beban kerja tinggi, 1 IU menyatakan komunikasi yang dilakukan sudah cukup baik. Hal tersebut sejalan dengan pendapat IT yang menyatakan kekurangan dalam komunikasi antara dokter, perawat dan pasien adalah beban kerja yang tinggi menyebabkan komunikasi yang terjadi kurang optimal sehingga dilakukan via telepon, sehingga hambatan yang mungkin terjadi adalah adanya mis skomunikasi antara dokter dan perawat.

Komunikasi saat serah terima pasien di RS X Jepara adalah 3 IU menyatakan komunikasi pada saat serah terima sudah efektif karena dilakukan dengan melihat pasien serta identitas/statusnya. 2 IU menyatakan serah terima dilakukan diruangan dengan memberi informasi berdasarkan status pasien, 1 IU mengatakan jika keadaan darurat serah terima dilakukan di ruang perawat. IT menyatakan bahwa serah terima pasien di RS X Jepara dilakukan hanya diruang perawat saja tanpa melihat langsung pada pasien karena beban kerja terlalu tinggi.

\section{Kotak 3}

"jika keadaan pasien banyak kami tidak sempat melakukan serah terima pasien dengan baik, terkadang hanya melakukan di nurse stasion saja"

"komunikasi efektif baik dan optimal, apabila serah terima pasien yang dilakukan oleh perawat memang sering dilakukan hanya di nurse stasion karena beban kerja mereka yang tinggi terkadang tidak sempat memeriksa langsung keadaan pasien"

\section{Peningkatan Keamanan Obat}

Berdasarkan hasil wawancara mendalam didapatkan bahwa sistem dan prosedur dalam penyimpanan obat yang dilakukan di RS X Jepara adalah IU menyatakan penyimpanan dilakukan di depo farmasi sesuai dengan urutan dan prosedur yang telah ditetapkan. IT 
menyatakan penyimpanan dilakukan pada masing-masing bagian seperti farmasi, laborat, radiologi, poliklinik, ruang perawatan, dan unit khusus dan dibedakan menurut bentuknya kemudian diletakkan dan disimpan di lemari terpisah sesuai dengan sifatnya dengan suhu yang telah disesuaikan.

Penatalaksanaan pemberian obat yang dilakukan di RS X Jepara adalah 2 IU menyatakan pemberian diberikan langsung oleh perawat yang bertugas di ruangan. 2 IU menambahkan pemberian dilakukan sesuai dengan instruksi DPJP, 1 IU menyatakan pemberian dilakukan dengan proses mengkonfirmasi pada keluarga dan pasien kemudian mengkonfirmasi kesamaan nama dengan gelang dan pemberian obat lalu meminta tanda tangan pada lembar konfirmasi, 1 IU menyatakan pemberian obat tertentu dilakukan dengan double check anatara dua petugas. IT menyatakan pemeberian obat dilakukan dengan memberitahu keluarga tentang tindakan yang akan dilakukan, kemudian melakukan pengecekan ulang, melakukan pemberian obat sesuai petunjuk, menandatangani lembar pemberian bersama pasien, dan mendokumentasikan hasil tindakan pada catatan perawatan.

Hambatan dalam penatalaksanaan pemberian obat di RS X Jepara, 1 IU menyatakan ada pemberian obat yang tidak sesuai karena kurangnya komunikasi saat serah terima pasien, 1 IU menyatakan hambatan saat melakukan serah terima, 1 IU menyatakan catatan medik tidak terbaca saat serah terima pasien, 1 IU menyatakan stok obat di farmasi habis, 1 IU menyatakan adanya retriksi dari pihak asuransi kesehatan, 1 IU menyatakan adanya obat yang memiliki efek samping alergi. IT menyatakan hambatan dalam penatalaksanaan pemberian obat di RS X Jepara adalah ketika pasien tidak memberitahukan riwayat alergi padahal pasien tersebut mengalami alergi obat.
Prosedur penatalaksanaan inform consent yang dilakukan di RS X Jepara adalah 1 IU menyatakan 3 IU menyatakan dilakukan komunikasi terlebih dahulu dengan pasien terkait tindakan dan resiko yang akan terjadi secara jelas sebelum pengambilan keputusan, 2 IU menyatakan dilakukan komunikasi secara lisan kemudian membuat check list sesuai dengan informasi yang didapatkan dan yang terakhir menandatangani lembar inform consent. IT menyatakan bahwa prosedur inform consent diawali dengan melakukan komunikasi dengan bahasa yang dapat dimengerti dan dipahami oleh pasien, terkait kondisi dan tindakan yang akan dilakukan, bila diperlukan dokter akan memberikan second opinion pada dokter lain. Setelah itu menandatangani inform consent oleh pasien.

Kotak 4

"penyimpanan sudah sesuai prosedur namun untuk pemberian obat terkadang ada beberapa obat yang seharusnya sudah dihentiksn, tapi karena kurang komunikasi saat operan kadang obat masih saja diberikan"

IU 2

"Sistem penyimpanan dan prosedur penyimpanan obat sudah sesuai prosedural dalam pelaksanaan pemberian obat sudah sesuai dengan prosedur tapi terkadang dalam pemberian ada hambatannya karena kesalahpahaman dalam komunikasi dan tidak menggali informasi riwayat alergi obat, kehabisan obat-obatan dibagian farmasi,obat yang diberikan ada retriksi dengan pihak asuransi"

5. Kepastian Tepat Lokasi, Tepat Prosedur dan Tepat Operasi

Berdasarkan hasil wawancara mendalam didapatkan bahwa pelaksanaan penandaan daerah operasi yang dilakukan di RS X Jepara adalah 4 IU menyatakan penandaan daerah operasi dilakukan oleh dokter operator sebelum operasi dan sebelum pasien diberikan obat anastesi, 2 IU menyatakan penandaan hanya dilakukan diwilayah organ yang memiliki 2 arah/2jumlah. IT menyatakan pelaksanaan penandaan daerah operasi 
dilakukan 9 jam sebelum operasi, dilakukan jika melibatkan 2 sisi kemudian menandai daerah operasi pada saat pasien masih dalam kondisi sadar, penandaan dilakukan oleh dokter dengan menggunakan spidol permanen.

\section{Pengurangan Risiko Infeksi terkait Pelayanan Kesehatan \\ Berdasarkan hasil wawancara} mendalam didapatkan bahwa upaya yang dilakukan dalam pengurangan risiko infeksi terkait pelayanan pasien yang dilakukan di RS X Jepara adalah semua IU menyatakan upaya dilakukan dengan cuci tangan sesuai dengan aturan WHO, pembatasan jam kunjungan, pemberian antibiotik secara rasional. Hal tersebut sesuai dengan pendapat IU yang menyatakan upaya pengurangan resiko infeksi dilakukan dengan cara mencuci tangan dengan baik dan benar serta sesuai dengan prosedur, pembatasan jam kunjungan serta sterilisasi alat operasi.

Hambatan yang dirasakan dalam melakukan upaya pengurangan risiko infeksi terkait pelayanan kesehatan di RS $X$ Jepara adalah 5 IU menyatakan hambatan berupa ketidakpatuhan petugas saat mencuci tangan, 1 IU menyatakan sterilisasi alat yang kadang tidak dilakukan. Hal tersebut sesuai dengan pendapat IT yang menyatakan hambatan dalam upaya pengurangan risiko infeksi di RS X Jepara adalah adanya ketidakpatuhan petugas saat mencuci tangan dan strerilisasi alat yang kurang baik.

Cara meningkatkan kebersihan untuk mencegah terjadinya infeksi di RS X Jepara adalah 6 IU menyatakan dengan cara saling mengingatkan untuk selalu mencuci tangan, adanya peringatan untuk selalu melakukan cuci tangan dan menyediakan air serta sabun untuk mencuci tangan.

\section{Pengurangan Risiko Pasien Jatuh}

Upaya yang dilakukan RS X Jepara dalam mengurangi risiko pasien jatuh adalah 3 IU menyatakan dengan memberikan gelang identitas disertai label resiko jatuh, 3 IU menyatakan dengan memberi penghalang pada tempat tidur pasien dan minimal harus ada 1 orang yang menunggu. Hal tersebut sesuai dengan pendapat IT yang menyatakan upaya yang dilakukan adalah dengan memberi gelang identitas pasien yang ditandai resiko pasien jatuh, menyediakan tempat tidur yang ada penghalang dan pasien minimal ditunggu oleh 1 orang anggota keluarga.

\section{Pembahasan}

\section{Komunikasi Efektif Tulis Baca} Konfirmasi

Komunikasi merupakan hal mendasar yang menjadi salah satu faktor keselamatan pasien dan kepuasan pelanggan. Berbeda dengan komunikasi lainnya seperti komunikasi di bidang pendidikan, bisnis dan lain sebagainya, komunikasi efektif dalam bidang pelayanan rumah sakit memiliki tingkat kompleksitas yang cukup tinggi. Hal ini disebabkan komunikasi yang terlibat sangat banyak, informasi yang dibutuhkan sangat banyak, serta menyangkut dengan emosi pasien/keluarga pasien, dan petugas kesehatan yang cukup tinggi.

Komunikasi efektif adalah proses komunikasi dimana komunikan mengerti apa yang disampaikan dan melakukan apa yang komunikator inginkan. Komunikasi efektif yang tepat waktu, akurat, lengkap, jelas, dan yang dipahami oleh resipien/penerima akan mengurangi kesalahan, dan menghasilkan peningkatan keselamatan pasien. Komunikasi dapat secara elektronik, lisan, atau tertulis. Komunikasi yang paling mudah mengalami kesalahan adalah perintah diberikan secara lisan dan yang diberikan melalui telepon, bila diperbolehkan peraturan perundangan. Komunikasi lain yang mudah terjadi kesalahan adalah 
pelaporan kembali hasil pemeriksaan kritis, seperti laboratorium klinis menelpon unit pelayanan pasien untuk melaporkan hasil pemeriksaan segera.

Perubahan perilaku pada tenaga medis yang sudah terbiasa dengan komunikasi ringkas juga membutuhkan proses untuk membuat perubahan. Kebijakan rumah sakit terkait peningkatan komunikasi efektif belum ada atau masih dalam proses pembuatan. Sedangkan SPO dan panduan terkait komunikasi efektif ini sudah ada dan sudah disosialisasikan kepada tenaga medis.

\section{Ketepatan Identifikasi Pasien}

Proses identifikasi pasien yang dilakukan secara benar dan tepat dapat mengurangi risiko kejadian yang tidak diharapkan (KTD) serta mengeliminasi kesalah sehingga dapat meningkatkan mutu pelayanan keelematan pasien di RS X Jepara.

Komunikasi pada saat serah terima pasien di RS X Jepara dapat dikatakan kurang baik. Hal ini sesuai dengan pendapat Catherine yang menyatakan contoh kelgagalan dalam komunikasi adalah Dalam Komunikasi yang dilakukan karena keterlambatan; adanya kegagalan suatu komunikasi dengan seluruh anggota tim dalam keperawatan, isi komunikasi antar perawat yang tidak jelas dan tidak dimengerti. Kegagalan dalam berkomunikasi menjadi salah satu faktor yang dapat menyebabkan ketidakpuasan perawat dan faktor suatu tujuan dalam komunikasi yang diharapkan tidak akan tercapai.

Kegiatan serah terima pasien adalah sarana komunikasi perawat dalam menerima dan menyampaikan suatu informasi secara lengkap,singkat dan jelas tentang tindakan-tindakan apa yang belum dilakukan dan apa saja yang sudah dilakukan perawat serta bagaimana perkembangan kesehatan apa yang terjadi pada pasien. Dalam pelaksanaannya kegiatan serah terima pasien membutuhkan peran komunikasi efektif. (jci) Belum optimalnya kegiatan serah terima pasien di RS X Jepara disebabkan karena belum adanya acuan dalam melakukan kegiatan operan jadi hanya mengacu kepada status rekam medik pada pasien. Sedangkan untuk kegiatan serah terima pasien untuk shift pagi ke sore dan shift sore ke malam sering dilakukannya masih secara tradisional, yaitu dengan kegiatan operan hanya di nurse station tidak ada konfirmasi langsung datang kepada masing-masing pasien.

\section{Komunikasi Efektif}

Suatu Komunikasi dikatakan baik antar perawat yaitu jika ada kerjasama yang baik saat melakukan serah terima pasien, yaitu perawat merangkum informasi secara lisan mengenai pasien yang menjadi tanggung jawab perawat diakhir shift. Dalam sistem serah terima yang dilakukan perlu dibentuknya suatu strategi komunikasi yang baik dan dapat dimengerti.

Komunikasi yang dilakukan secara tidak efektif dapat menyebabkan terjadinya kesalahan dalam penanganan dan pemberian tindakan serta obat kepada pasien sehingga berdampak pada kerugian bagi pasien dan rumah sakit. Komunikasi efektif dapat memudahkan petugas kesehatan dalam memberikan penanganan kepada pasien.

\section{Peningkatan Keamanan Obat}

Pada tahun 2001 dalam laporan FDA Safety, Thomas Maria R, et al menemukan bahwa yang menjadi penyebab terjadinya kesalahan obat adalah komunikasi (19\%), pemberian label $(20 \%)$, nama pasien yang membingungkan (13\%), faktor manusia $(42 \%)$, dan disain kemasan (20,6\%). Kesalahan dalam pemberian obat dapat berakibat pada over dosis, salah rute obat salah tekhnik, dan kesalahan dalam monitoring. 
Peningkatan kemanan obat yang dilakukan di RS X sudah baik dan sudah sesuai prosedur. Komunikasi yang dilakukan dengan menggunakan bahasa sederhana yang mampu dipahami oleh pasien dan keluarg pasien dapat mencegah terjadinya kesalahan dalam pemberian obat yang dapat mempengaruhi upaya keselamatan pasien di RS X Jepara, selain itu komunikasi yang baik dan efektif dapat mempengaruhi kepuasan pasien dalam hal pelayanan kesehatan yang diterima yang berdampak pada meningkatnya mutu pelayanan kesehatan RS X Jepara.

\section{Kepastian Tepat Lokasi, Tepat Prosedur dan Tepat Pasien Operasi}

Komunikasi dalam proses penandaan tepat lokasi daerah operasi merupakan bagian penting dalam proses pelayanan keselamatan pasien. Komunikasi yang mendukung keselamatan tidak terlepas dari standar dan prosedur komunikasi yang digunakan dan aspek keselamatan yang diinformasikan. Komunikasi yang akurat tentang pasien harus diinformasikan pada saat operan jaga, kurangnya informasi ataupun tidak tersampaikannya informasi penting terkait kondisi terkini pasien dapat menimbulkan risiko terjadinya kesalahan dan ketidaksinambungan asuhan keperawatan pada pasien.

Menurut Kemenkes, salah lokasi, salah prosedur, salah pasien operasi merupakan sesuatu yang mengkhawatirkan dan sering terjadi di rumah sakit. Kesalahan ini akibat dari komunikasi yang tidak efektif atau tim bedah yang kurang atau tidak melibatkan pasien saat penandaan lokasi. Di samping itu, ada beberapa faktor yang sering terjadi, antara lain: pengkajian pasien yang tidak adekuat, penulisan ulang catatan medis tidak adekuat, budaya yang tidak mendukung komunikasi antar anggota tim bedah

\section{Pengurangan Risiko Infeksi terkait Pelayanan Kesehatan}

Kepatuhan merupakan tingkat dimana seseorang berperilaku sesuai dengan apa yang disarankan dan sesuai dengan apa yang menjadi kewajibannya. Kepatuhan seorang karyawan berpengaruh terhadap berjalan dan tidak berjalannya suatu program dan dapat mempengaruhi pencapaian tujuan organisasi tempatnya bekerja. Kurangnya kepatuhan petugas kesehatan terhadap SOP dan rendahnya perilaku kebersihan merupakan salah satu kendala pada upaya keselamatan pasien di RS X Jepara. Mencuci tangan sebelum dan sesudah tindakan merupakan salah satu upaya yang dapat dilakukan untuk mengurangi jumlah mikroorganisme yang ada di tangan sehingga penyebaran infeksi dapat dikurangi.

Kurangnya kepatuhan terhadap SOP dan kurangnya perilaku tentang patient safety sangat menjadi kendala untuk berjalanya program sasaran keselamtan pasien di RS. Mencuci tangan dilakukan sebelum dan sesudah melakukan tindakan keperawatan walaupun memakai sarung tangan dan alat pelindung diri lain. Tindakan ini untuk mengurangi mikroorganisme yang ada di tangan sehingga penyebaran infeksi dapat dikurangi.

\section{Pengurangan Risiko Pasien Jatuh}

Menurut Potter \& Perry, 2009 beberapa intervensi yang dapat dilakukan perawat untuk mencegah terjadinya jatuh pada pasien antara lain; Mengorientasikan pasien pada saat masuk rumah sakit dan menjelaskan sistem komunikasi yang ada, bersikap hati-hati saat mengkaji pasien dengan keterbatasan gerak, melakukan supervise ketat pada awal pasien dirawat terutama malam hari, memberikan alas kaki yang tidak licin, memberikan pencahayaan yang adekuat, memasang pengaman tempat tidur terutama pada pasien dengan penutunan kesadaran dan gangguan mobilitas, dan menjaga lantai kamar mandi agar tidak licin. 
Kejadian pasien jatuh dapat disebabkan karena buruknya komunikasi. Komunikasi yang buruk merupakan penyebab yang paling sering menimbulkan efek samping di semua aspek pelayanan kesehatan, sehingga menimbulkan permasalahan dalam pengidentifikasian pasien, kesalahan pengobatan dan transfusi serta alergi diabaikan, salah prosedur operasi, salah sisi bagian yang dioperasi, semua hal tersebut berpotensi terhadap terjadinya insiden keselamatan pasien dan dapat dicegah dengan meningkatkan komunikasi.

\section{KESIMPULAN}

Pelaksanaan komunikasi efektif Tulis Baca Konfirmasi (TBK) dalam upaya keselamatan pasien, identifikasi pasien, peningkatan keamanan obat, ketepatan lokasi, serta upaya pengurangan risiko infeksi yang dilakukan di RS X Jepara sudah diterapkan namun dalam pelaksanaannya belum optimal . Rekomendasi pada penelitian ini adalah perlunya peraturan/kebijakan terkait komunikasi TBK serta perlunya pelatihan terkait komunikasi TBK di RS X Jepara.

\section{DAFTAR PUSTAKA}

1. Karen S. Kesten. Role-Play Using SBAR Technique to Improve Observed Communication Skills in Senior Nursing Students. Journal of Nursing Education; 2011. 50 (2).

2. Optimalisasi Proses Koordinasi Program Keselamatan Pasien (Patient Safety) di Rumah Sakit X Surabaya Optimization Of Coordinating Process Of Patient Safety ,m Program In Hospital X Surabaya . Jurnal Administrasi Kesehatan Indonesia. Juli-September 2014. 2(3)

3. Permenkes RI No.169 tahun 2011 tentang keselamatan pasien.
4. Basrowi S. Metode Penelitian Kualitatif Perspektif Mikro. Surabaya: Intan Cendekia; 2002.

5. Hargie dan Dixon, Skilled Interpersonal Communication: Research, Theory and Practice. Hove: Brunner Routledge: 2004.

6. Onong Ucjhana Effendy, Ilmu Komunikasi Teori dan Praktek. Bandung:Remaja Rosda Karya:2005.

7. Deddy Mulyana Ilmu Komunikasi: Suatu Pengantar. Bandung : Remaja. Rosdakarya:2007.

8. Cahyono,Suharjo B. Membangun Budaya Keselamatan Pasien dalam Praktik Kedokteran. Yogyakarta : Kanisius. Departemen:2008

9. Strauss, G and Sayles. Manajemen Personalia Segi Manusia dalam Organisasi. Jakarta: PT Pustaka Binamana Pressindo; 1997.

10. Needleman, et al. Information Seeking in Primary Care: How Physician Choose Which Clinical Question to Pursue and Which To Leave Unanswered. Med. Decision Making, Apr-Jun 2006; 15(2), pp: 113-119.

11. O'donnel, Orla dan Richard Boyle. Understanding and Managing Organizational Culture. Dubin Ireland:I nstitute of Public Administration; 2008.

12. Sorra JG, L., Streagle S, Famolaro T, Yount N, Behm J. AHRQ Hospital Survey on Patient Safety Culture: User's Guide: Agency for Healthcare Research and Quality; 2016.

13. Nursalam. Proses dan Dokumentasi Keperawatan, Konsep dan Praktek. Jakarta: Salemba Medika; 2011.

14. Strauss, George and Sayles Leonard. Manajemen Personalia (Terjemahan Rochmulyati Hamzah). Jakarta: PPM; 2002.

15. Sabarguna, Boy. Sumber Daya Manusia Rumah Sakit. Konsorium Rumah Sakit Islam Jateng-DIY; 2006. 
16. Gibson, dkk. Perilaku-Struktur-Proses.

Jakrta: Binarupa Aksara; 1997. 